\title{
Successful management of membranous duodenal stenosis by endoscopic balloon dilation and membrane resection with an insulated-tip knife
}

A 14-month-old girl was admitted to our department because of repeated nonbilious vomiting for $>3$ months and malnutrition. Upper gastrointestinal radiography showed partial obstruction of the duodenum ( $\triangleright$ Fig.1). Gastroscopy confirmed a membranous duodenal stenosis with an opening of about $3 \mathrm{~mm}$ in diameter, and no view of the duodenal papilla above the membrane ( $\triangleright$ Fig. 2 a). We performed both balloon dilation and membrane resection ( $\vee$ Video $\mathbf{1}$ ).

First, endoscopic balloon dilation was carried out to locate the duodenal papilla ( Fig.2b), which was in the 10 o'clock position and $1 \mathrm{~cm}$ below the membrane (>Fig.2c). Then, following submucosal injection of diluted epinephrine (1:10000), a circumferential incision was performed contralaterally to
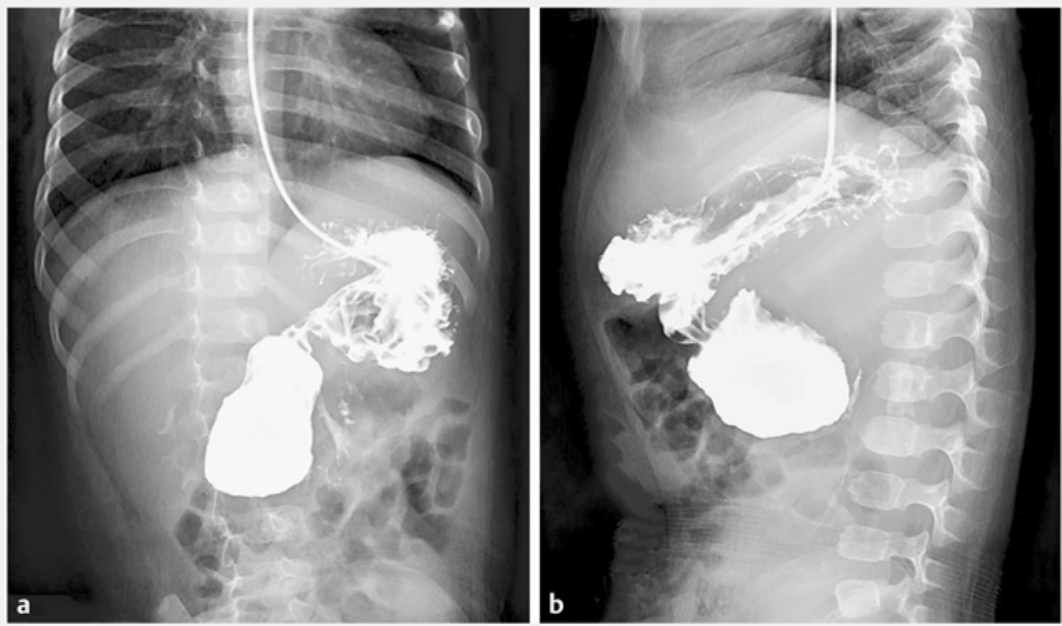

Fig. 1 Upper gastrointestinal radiography showed partial obstruction of the duodenum. a Frontal view, b Lateral view.
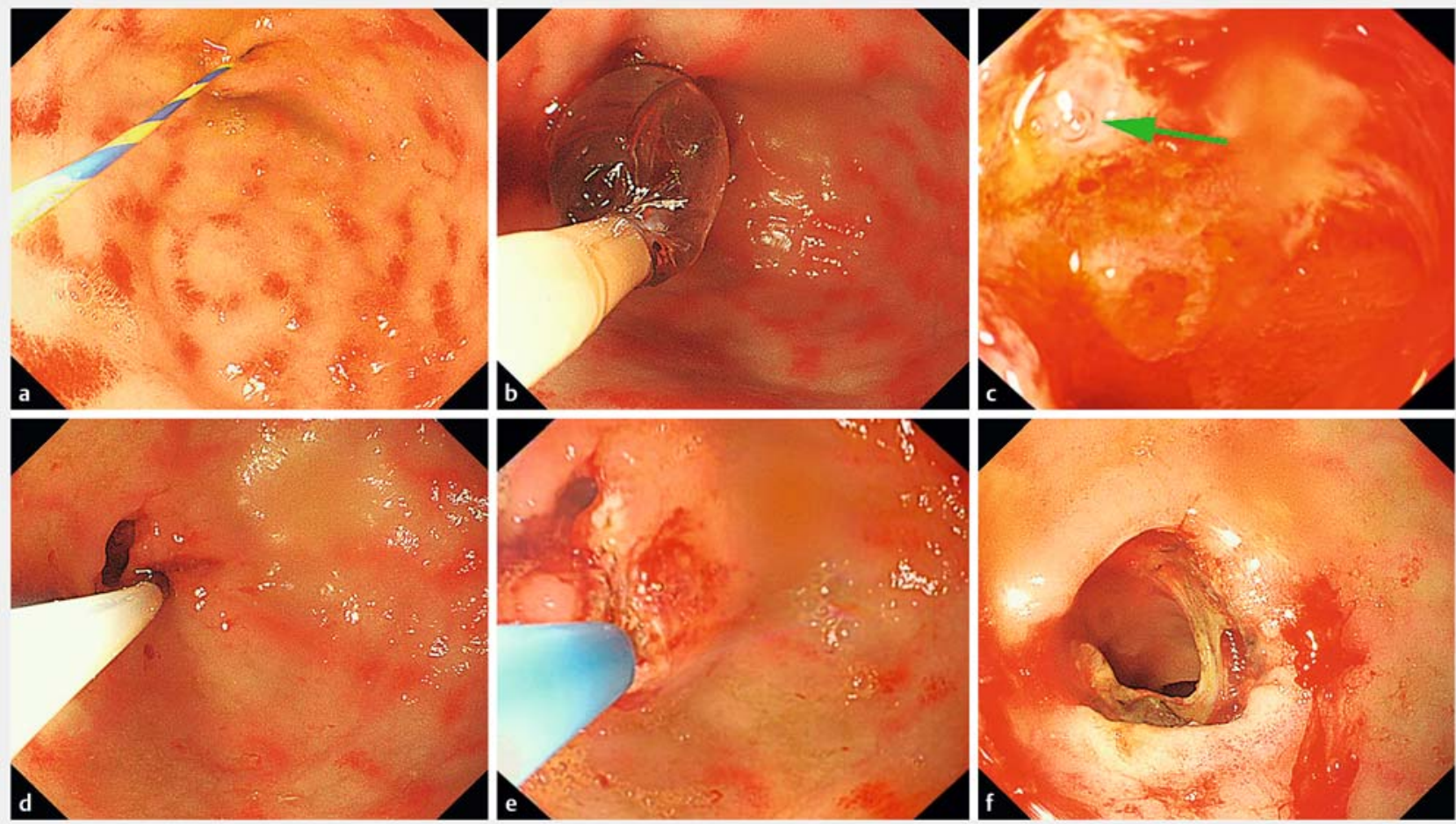

Fig. 2 Endoscopic images. a Membranous duodenal stenosis with an opening of about $3 \mathrm{~mm}$ in diameter. b Balloon dilation of the membrane. c Location of the duodenal papilla (green arrow), showing bubbles that escaped when the right upper abdomen was pressed gently. $\mathbf{d}$ Submucosal injection of diluted epinephrine. e Membrane resection with an insulated-tip knife. $\mathbf{f}$ The opening of the membrane was increased so that the endoscope could pass through without resistance. 


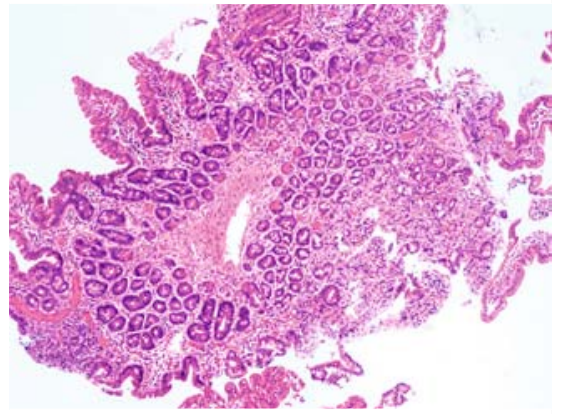

- Fig. 3 Pathological examination showed that muscle tissue was present in the resected membrane (hematoxylin and eosin staining, $\times 40)$.

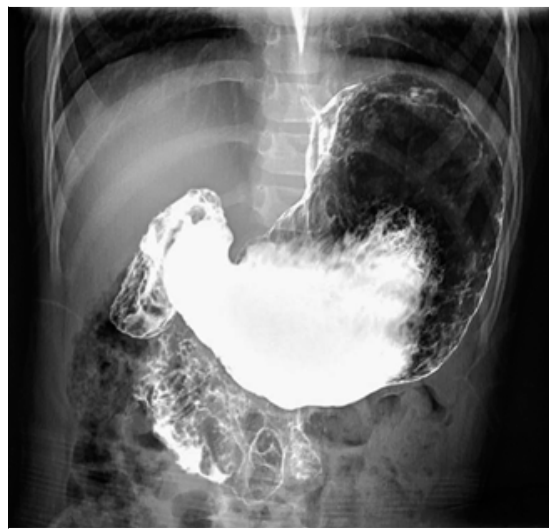

- Fig. 4 Follow-up upper gastrointestinal radiography at 6 months post-procedure showed that the duodenal obstruction had disappeared.

the duodenal papilla using an insulatedtip knife ( $\mathbf{F i g . 2 d , e ) . ~ T h e ~ r e s e c t e d ~}$ membrane was removed and the opening was increased to $12 \mathrm{~mm}$ in diameter ( $\mathbf{F i g . 2 f ) . ~ A ~ n a s o j e j u n a l ~ t u b e ~ w a s ~ i n s e r t - ~}$ ed through the opening.

The girl recovered uneventfully after endoscopic treatment, and symptoms of vomiting gradually disappeared. Pathological examination showed that muscle tissue was present in the resected membrane (-Fig. 3 ).

At the 6-month follow-up visit, her body weight had increased by $3.0 \mathrm{~kg}$, and upper gastrointestinal radiography showed that the duodenal obstruction had disappeared (> Fig.4).

Membranous duodenal stenosis is a common pediatric gastrointestinal abnormality, with an incidence of 1:10 000-40 000

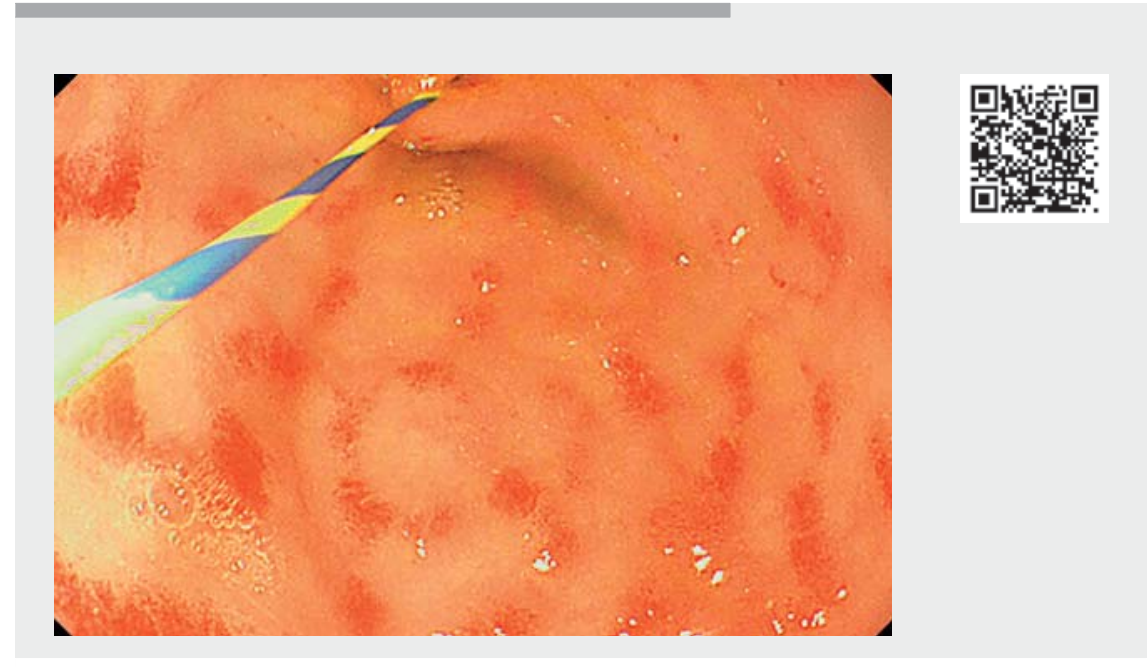

$\checkmark$ Video 1 Management of membranous duodenal stenosis by endoscopic balloon dilation and membrane resection with an insulated-tip knife.

[1], which has traditionally been managed either via laparotomy or laparoscopic surgery. Endoscopic treatment of sporadic cases has been reported [2-4]. However, balloon dilation alone, without membranectomy, may result in stricture recurrence, whereas membranectomy cutting techniques cannot completely avoid possible injury to the duodenal papilla or even perforation, especially if the duodenal papilla is below the membrane. Given the limited space and thinner duodenal wall in children, submucosal injection prior to membrane resection would help to avoid cutting too deeply and ensure safe removal of the lesion.

Endoscopy_UCTN_Code_CCL_1AB_2AZ_3AZ

Acknowledgments

The authors thank Shanghai Municipal Population and Family Planning Commission (China) (201840341) for their support.

\section{Funding}

Shanghai Municipal Population and Family Planning Commission, http://dx.doi.org/10.13039/ 501100008410

201840341

\section{Competing interests}

The authors declare that they have no conflict of interest.

The authors

Xing Wang ${ }^{1}$, Haifeng Liu', Guogang $\mathrm{Ye}^{2}$, Zhibao Lv' ${ }^{2}$, Zhihong $\mathrm{Hu}^{1}$

1 Department of Digestive Endoscopy Center, Shanghai Children's Hospital, Shanghai Jiao Tong University, Shanghai, China

2 Department of General Surgery, Shanghai Children's Hospital, Shanghai Jiao Tong University, Shanghai, China

\section{Corresponding author}

\section{Haifeng Liu, MD, PhD}

Department of Digestive Endoscopy Center, Shanghai Children's Hospital, Shanghai Jiao Tong University, 355 Luding Road, Putuo District, Shanghai 200062, China haifengliush@aliyun.com

\section{References}

[1] Huang MH, Bian HQ, Liang C et al. Gastroscopic treatment of membranous duodenal stenosis in infants and children: report of 6 cases. J Pediatr Surg 2015; 50: 413-416 
[2] Goring J, Isoldi S, Sharma S et al. Natural orifice endoluminal technique (NOEL) for the management of congenital duodenal membranes. J Pediatr Surg 2020; 55: 282-285

[3] van Rijn RR, van Lienden KP, Fortuna TL et al. Membranous duodenal stenosis: initial experience with balloon dilatation in four children. Eur J Radiol 2006; 59: 29-32

[4] Nose S, Kubota A, Kawahara $\mathrm{H}$ et al. Endoscopic membranectomy with a high-frequency-wave snare/cutter for membranous stenosis in the upper gastrointestinal tract. J Pediatr Surg 2005; 40: 1486-1488

\section{Bibliography}

Endoscopy 2022; 54: E256-E258

DOI 10.1055/a-1506-2785

ISSN 0013-726X

published online 8.6.2021

(C) 2021. Thieme. All rights reserved.

Georg Thieme Verlag KG, Rüdigerstraße 14,

70469 Stuttgart, Germany

\section{ENDOSCOPY E-VIDEOS}

https://eref.thieme.de/e-videos

口回 Endoscopy E-Videos is an open access online section, 回躲: reporting on interesting cases and new techniques in gastroenterological endoscopy. All papers include a high quality video and all contributions are freely accessible online. Processing charges apply (currently EUR 375), discounts and wavers acc. to HINARI are available.

This section has its own submission website at

https://mc.manuscriptcentral.com/e-videos 